\title{
THE COMPARATIVE ANALYSIS OF INTERACTIVE TECHNOLOGIES
}

\author{
Olga Sydoruk \\ Department of Foreign Languages for the Science Faculties \\ Odessa I. I. Mechnikov National University \\ 2 Dvoryanskaya str., Odessa, Ukraine, 65082 \\ olgasu@ukr.net
}

\begin{abstract}
The article discloses the problem of interactive technologies application at Ukrainian and German higher educational establishments that has been under study for the last twenty years. The definition of the notion "interactive technologies" and different interpretations of this concept that were given by Ukrainian and foreign scholars are highlighted. The peculiarities and varieties of interactive technologies (simulations, role-games, discussions, debates, cooperative and group learning, brainstorming, projects, graffiti, synthesis of ideas, collaborative work, fishbowl, roundabout and others) are brought to light.

The article singles out similarities and differences of interactive technologies application in Ukraine and Germany. The author emphasizes on the organization of interactive activities at the lectures, the purpose of use of each kind of interactive technology in Ukrainian and German educational process. The detailed study, analyses and comparison of experience of foreign language teachers training in the above-mentioned countries are carried out.

Keywords: Ukraine and German, educational process, communication skills improvement, interpersonal communication, foreign languages teachers, team work, cooperation.

\section{Introduction}

Due to creation of the united European educational space, general recognition of diplomas and qualifications, understanding of preferential character of new knowledge, modernization of foreign pedagogical education, the question about the necessity of studying and realizing the comparative analysis of technologies and methods, used in Germany at training teachers of foreign languages appears. The study, analysis and comprehension of experience of training foreign language teachers in Germany allows to reveal certain innovative methods and holds that may favor the improvement of Ukrainian higher educational system. The realized analysis of scientific-pedagogical sources proves that the problem of specificity of using interactive technologies at higher educational institutions of Germany has not been properly considered till today and introduction of German experience may favor the practical improvement of content, operative and scientific-methodological components of foreign language teachers training in Ukraine.
\end{abstract}

\section{Analysis of literary sources}

The analysis of scientific works of the modern scientists [1-4], who work on the problem of interactive technologies introduction in the educational process of Ukrainian higher educational institutions, give reasons to state that the development of modern higher education and education in whole is not possible without using these technologies in practical activity of an educational institution that are defined as: learning technologies, directed on attainment of intersubjective interaction by active, creative, rational activity of participants of the learning-upbringing process, have a problem-searching nature, activate knowledge, thoughts, feelings, conscious behavior, interest to learning and favor creation of the atmosphere of cooperation, formation of abilities, skills, experience.

The foreign scientists [5-10] interpret interactive technologies as learning ones that provide active interpersonal interaction, characterized by mutual influence and mutual replacement of communication partners, whose verbal behavior forms a base of an activity and is manifested in quantitative changes, motivating them to speak foreign language without efforts and with incitement due to taking into account personal interests and needs and combining in such a way social and emotional components of the learning process that for certain guarantees a success for everyone who studies. 
The short description of the system of teachers training, types of technologies and disciplines that these technologies are applied to [5].

The definition and detail description of interactive technologies and their classification $[1,3]$.

The types of interactive technologies, used in HEIs of Ukraine [2].

The definition of the notion "interaction", "interactive activity", "technologies and methods" $[6,9]$.

The types of interactive technologies, used in Germany, and their features [7].

The definition of the essence of interactive activity in HEIs and most effective technologies, used there with examples from a school [8].

The detail description of activities in English and technologies that help to fix one or another competence [10].

The use of interactive technologies in higher school and methods of their assessment in Ukraine [4].

\section{Aim and tasks of research}

The aim of research is the comparative analysis of the types of interactive technologies, used at foreign language teachers training in Germany and Ukraine.

Tasks of research: scientists;

- to study the definition of the notion "interactive technologies", used by native and foreign

- to reveal technologies, most often used in the learning process of Ukrainian and German HEIs;

- to find common features and differences in using interactive technologies in Germany and Ukraine.

\section{Materials and methods of research}

In the process of assessment of native and German literary sources we used empirical methods, namely, analysis, comparison, analogy, systematization. At visiting the Free university of Berlin I had a possibility: to observe interactive technologies application, take part in activities that interactive technologies were used at; have a conversation with 3, 4, 5 year students and teachers of the university as to features and effectiveness of interactive technologies.

\section{Results of research}

I chose Germany, because:

1. Higher education of Germany is a combination of centuries-old university traditions with most modern technologies.

2. Specialists' training is grounded on the unity of four methodological approaches:

- interdisciplinary approach is directed on the development of worldview width, non-standard thinking, abilities to assess the effectiveness of one or another innovation, to organize its practical realization that allows to teach students to acquire knowledge in different fields independently and to use theoretical knowledge for solving real practical problems;

- integrative approach due to the close connection with schools provides mastering of pedagogical activity methodology and getting of creative abilities and skills;

- practice-oriented innovative approach provides mastering of the full cycle of innovative activity and development of professionally important qualities of specialists, correspondent to new forms of labor organization under conditions of innovative pedagogical activity;

- problem-oriented approach to learning allows focus students' attention on an analysis and solution of concrete problem situations, motivates them to mastering knowledge from different fields, forms creative abilities, involves into scientific-research activity.

At scientific probation that provided visiting lectures of teachers in the Free university of Berlin I had a possibility to convince myself in the effectiveness of interactive technologies and their positive role in the personal development of not only a student but also a teacher.

These very parameters, "aim and course of technology", from my point of view, are the main parameter that each teacher is concentrated on at preparing to an activity with interactive 
technologies use. At the same time these very parameters help features in technologies, so they contain many details.

Let's consider differences in using interactive technologies in Ukraine and Germany.

\section{1. Work with audio materials}

Ukraine

Audio materials act:

1) as an instrument of fixing phonetic, lexical, grammatical and stylistic skills at more advanced stages;

2) as an instrument for communicative abilities development;

3 ) as an instrument that takes away psychological discomfort and raises working capacity;

4) as an instrument for checking up a text (song or verse) understanding - its translation by joint efforts under teacher's guidance.

Differences: the use of audio materials provides checking up a text understanding, fixing lexical, grammatical, stylistic skills, taking psychological discomfort away.

Audio materials act:

\section{Germany}

1) as an instrument of acquaintance with another culture, customs, described in a text (song, verse); with an artist's personality, with a music genre;

2) as an instrument of training communicative skills using dialog or dramatization;

3) as an instrument of an author's biography presentation, facts from it.

Differences: audio materials act as an instrument of: an author's biography presentation, acquaintance with another culture, with a music genre, training communicative abilities and skills.

\section{2. Work with video materials}

\section{Ukraine}

Aim: to increase motivation, interest, to diversify work types and forms, to favor attention concentration, to improve materials perception due to the synchronous involvement of auricular and visual analyzers.

Organization: the work with video materials provides three stages: before viewing, at viewing, after viewing.

Tasks before viewing: to find a text correspondent to a video story, to read and to name problems, considered in it and will be demonstrated in this video story; to fill gaps in a text, to find common and discordant features, concerned to a film and to discuss them; to compose parts of cues or dialogues, correspondent to a film content, written on cards. Tasks at viewing: to desynchronize a video story - at first it is viewed without image and one must try to guess what was earlier, what happens now and will be further, how characters of a story look, then to check up guess correctness; next task - a video story is viewed without sound, one must try to guess what will happen further. Next tasks with cards: to determine logic and chronologic succession of events, phenomena, facts on the base of a video, choice of correspondent expressions, used in it, to compose a text on the base of what has been seen, to take interview, to play a role game. Problems, considered in a film are commented, interpreted by students with their own ideas presentation.

Tasks after viewing: students compare cues, ideas of characters, used in a film with ones in a text, received from a teacher; they read a small text, composed on the base of a video, distribute information in blocs (heroes, location, debatable question, situation, implication).

Differences: Check up of a video story content understanding using text tasks.

\section{Germany}

Aim: formation of communicative competence and comprehension competence, study of cinema/literature genres and their influence on a spectator.

Organization: the work with video materials provides carrying out tasks before and after viewing. 
Tasks before viewing: having viewed a promotional reel from a film, talk about first impressions from a film, characters, determines a genre, audience and state does all that inspire them for further viewing or not.

Tasks after viewing:

Students reconstruct separate elements from viewed fragments of a film of dialogs, situation: find keywords or fragment; make guesses what will be further according to a plot; analyze sound, image; talk about living conditions of characters, how do they influence events that happen, directly characters, which values and norms were shared by characters; analyze a film (duration, perspective change frequency); play in role a fragment or whole film (perspective shift to the present). Students discuss characters (main and secondary ones), their appearance, ideas, interaction, retell according to a plan, analyzes a music, chosen to a film, assembling, staging, describe special parts of a story, events course), accent, use of idiomatic expressions, constructions, certain intonation, voice beyond a frame, compose a dialog according to certain fragment, make a dubbing. They reconstruct plots from a film (introduction, exposition, problem), make a poster of it, write a review, invent an adventure, based on an episode from a film; compare a screened version with a book one and point out a topic, considered by a film; write a critique on it, based on an analysis of audio, video and sound effects, use of a cultural and historical background, analysis of gender and age features of characters.

Differences: students study cinema/literature genres, their influence on an audience, types of emotional reactions, behavior, inherent to certain situation; carry out different types of tasks, directed on different competences formation.

\section{3. Use of simulations (imitations)}

\section{Ukraine}

Aim: an illustration of certain phenomena and mechanisms of making decisions by representatives of social institutions, possibility to get used to a problem, to understand it from inside, recognize casual connections.

Organization: a teacher with students choose a phenomenon, theme for simulation. A teacher gives students information for playing roles masterfully. At the beginning a teacher makes an introduction to simulation then it takes place. At the end a teacher together with students discuss received results, analyze playing roles with different participants.

Differences: an accent is made on certain phenomena and mechanisms of making decisions by representatives of social institutions; they have a possibility to get used to a problem, to understand it from inside, to recognize casual connections. Students know roles and prepare to their presentation beforehand.

\section{Germany}

Aim: to provide successful interpersonal interaction, critical thinking development, experience for future, improvement of communicative competence. Organization: a teacher spends up to 15 hours for this work, at first he explains rules then together with students forms a list of necessary materials for decoration, list of vocabulary that must be used, this vocabulary is trained at lessons during certain time using different tasks, after that dialogs are composed and trained. When a day of simulation comes, a teacher gives roles as cards with a surprise and discusses them with students. Sometimes a film is made of a simulation. After ending, a teacher discusses the following questions with students: how realistic did they play roles, which advantages are in this technology use and what positive moments were at a simulation.

Differences: an accent is made on a behavior of people of different professions. Students are acquainted with a topic of simulation, but they don't know which role they will play at it, receiving a role is a surprise for them.

\section{4. Use of role game}

\section{Ukraine}

Aim: determination of student's attitude to a concrete life situation, getting an experience through experience, development of imagination, critical thinking, ability to find alternative decisions. 
Organization: students start from reading texts in roles, form short expressions, answers of certain person. There are observers and participants. A teacher informs students as to a topic of role game but doesn't distribute roles. This work is realized as a scenario. It is presented as a dramatization at which participants act partially spontaneously, without prepared dialogs or as a story, at which a presenter introduces an essence of thing and other students play roles and open its content. At the end there takes place a detail analysis and discussion of gained experience, ideas and feeling by participants and observers.

Differences: there is no preliminary preparation. At the end a detail analysis and discussion of gained experience, ideas and feeling by participants and observers is carried out.

\section{Germany}

Aim: overcoming of language barrier and fear at expression on a chosen topic using necessary vocabulary on it.

Organization: this work is received as a home task for give students a possibility to prepare well. At the following lession a teacher checks up tasks, namely student's role game in foreign language. Personal sincere expressions by a teacher and by students give a possibility to feel oneself unrestrained, to overcome language barrier and fear, to use a necessary vocabulary on a chosen topic. All students' expressions are assessed by a teacher using a scale with points. After this work a discussion for correcting mistakes takes place, in such a way, skills of communication at which different types of emotions, behavior and own experience are used, are improved. The motivation of this work is a possibility to be in such situation abroad.

Differences: preliminary preparation, fixation of answers, improvement of communicative skills, use of different emotions and behavior, studied vocabulary and own experience. At the end of a game a teacher analyzes it using a scale with points.

\section{5. Use of discussion}

\section{Ukraine}

Aim: it favors critical thinking development, formation of own worldview, deepens knowledge on a discussed problem, teaches deep understanding of a problem, arguing an independent position, acknowledgment of opponent's successful arguments.

Organization: a teacher together with students chose a theme, form a plan and rules of discussion. A teacher gives a literature, where points of view of different scientists are presented, for independent mastering at home, forms a list of questions for guiding a discussion and attracting attention to a problem. At the end conclusions are made, most convincing arguments are separated and calculated.

Differences: all students take part in a discussion. A material with points of view of different scientists is prepared beforehand. Students consider it and add own arguments as to presented points of view, deepening knowledge on a problem. A distinct plan, organization, guidance of discussion is provided by a teacher.

\section{Germany}

Aim: it favors creativity, successful interpersonal communication and cooperation of students, ability to express and argue own idea, make decisions taking into account certain arguments and circumstances, to treat another point of view with tolerance, to widen worldview, to solve a conflict situation, to improve such competences as subject, social ones and decisions making.

Organization: A topic for discussion is chosen. At that contradictions must be overcome and an alternative or correct decision must be found. A teacher must visualize a debatable question, give explications about rules of discussion, own role. Certain time is given for thinking and discussion, participants walk along a lecture hall, speaking on chosen topic, each expression is put to a list. When the time is over, conclusions about contradictions and commonness in thoughts and their bases were made.

Differences: only ones who want takes part in a discussion. Students prepare to a discussion in a lecture hall, where they can move freely. Each expression is put to a list and then discussed. At the end, conclusions about contradictions and commonness in thoughts and their bases were made. 
This work favors creativity, successful interpersonal communication. A teacher doesn't impose a distinct plan of discussion but only guides it using directing questions.

\section{6. Use of debates}

\section{Ukraine}

Aim: to be able to express own point of view, listen to an opposite side attentively, publicly ground the correctness of own position and incline opponents to own side; solve problems together.

Organization: at the beginning a teacher gives a topic of debate and literature for it that helps students in preparation, unites students in two groups "for" and "against", announces rules, one group must prepare questions for another. Judges may be invited to assess speeches (other students, not included in the groups "for" and "against"), who make conclusions and speak final words. If a common decision is necessary, a vote is carried out.

Differences: at the beginning a teacher gives a topic of debates and literature for it that helps students in preparation, after consideration of a topic, he unites students in two groups "for" and "against". A student argues certain point of view depending on a group that he belongs to.

\section{Germany}

Aim: the main thing is not to be able to express arguments but skillfully defend and ground own position, to learn to compare arguments, treat opposite ones with tolerance and react correspondingly, to observe a democratic principle, to recognize the significance of ideas exchange for making decisions.

Organization: debate is carried out after studying certain number of topics. A teacher gives students a time to think about what a position they want to occupy: "for", "against" or to be "independent observers" that form a list that contains arguments "for" and "against" that are further discussed. Groups prepare for some time. Numbers of students with opposite opinions are not obligatory equal. Students chose two barristers from the opposite groups, who seat near teacher and at the end, must perform a speech from represented team. An independent observer seats behind them, at the end of discussion he must give a report and comments. If any opponent changes an idea during a debate, he may go to the other group. When all arguments "for" and "against" are exhausted, barristers from each group perform speeches and also answer opponents' questions. After that a vote as to considered problem solution is realized.

Differences: Students have a possibility to choose a position that they consider as correct or change a point of view at debate. "Reporters" are present in a group, who give their reports and comments, and "barristers", who perform speeches and must answer opponent's questions giving reasons.

\section{7. Technologies of collective-group study}

Incomplete sentences

\section{Ukraine}

Aim: to overcome stereotypes, to speak freely and briefly about offered themes, to study to work on a form of own ideas expression, comparing them with other ones.

Organization: students are placed by circle; having chosen a topic or question, a teacher form an incomplete sentence and offer students to complete it, starting from an offered formula.

Differences: this work is realized for making conclusions as to a discussed theme and gives everyone a possibility to speak about what he has understood.

\section{Germany}

Aim: to train lexical and grammatical skills.

Organization: students are placed by circle; having chosen a topic for communication with students, a teacher form an open sentence using grammatical or lexical construction that student must continue. Next student repeats this sentence and adds own one. If anyone makes mistakes at building a sentence, he goes out of a team. Such task may be also performed in written form.

Differences: students train certain lexical or grammatical construction at discussing a conversational theme. 


\section{8. Brain storm}

\section{Ukraine}

Aim: to be able to elaborate several decisions as to a concrete problem, to demonstrate creativity, to be able to express thoughts logically, to gather as more ideas as possible about a problem during a limited period of time.

Organization: a teacher writes a problem or question on a table, using a main or starting work that concerns it. Students must express ideas, comments, connected with this problem and discuss them.

Differences: students solve a problem question using expressed ideas, comments that are discussed and assessed.

\section{Germany}

Aim: to favor better memorization of words, phrases, dictums, verbs with their management by creating visible associations, sentence words images with a word. This technology helps to separate more important information from less important one and arrange it logically.

Organization: a teacher writes a word or topic on a table, students choose words and dictums, associated with it, then create sentences or put questions to these words to memorize words and dictums of a studied topic.

Differences: students choose words and dictums, associated with a studied topic, then create sentences or put questions to these words to memorize them better.

\section{9. Cooperative study}

Project

\section{Ukraine}

Aim: to be able to think independently, to find and solve problems, to increase students' interest to foreign language study using the development of internal motivation, creative abilities, research skills, ability to self-realization, to attract students to a dialog between cultures as an instrument of intercultural interaction, to improve communicative competence; a possibility to express thoughts, to speak about oneself, one's life, interests, hobbies.

Organization: a teacher finds a problem that needs for research realization and has a practical importance of results; at solving it, an independent, individual, group work is used. A teacher may adapt tasks for a student. Work stages are realized as following:

1) work planning in a lecture hall;

2) work realization beyond it;

3) work in a lecture hall;

4) presentation of a project

5) assessment and control of results.

Differences: the improvement of communicative competence by students' attraction to a dialog between cultures as an instrument of intercultural interaction. Students receive a possibility to express thoughts, to speak about oneself, one's life, interests, hobbies. A studied problem needs for research realization and has a practical importance of results; at solving it, an independent, individual, group work is used. A teacher may also adapt tasks for a student.

\section{Germany}

Aim: to unite interests, to satisfy needs in self-realization, to add motivation for studying any topic.

Organization: this type of activity is carried out by a teacher and a student and may combine several diverse methods. A group or a course may take part in a project. It is realized through the following stages: a case, when a student received some experience, is chosen; ideas about a project realization are shared; aim, tasks, subject of an action that must be realized during certain period of time are set, tasks are distributed, students elaborate a plan, work on its realization, collect results, received at individual and independent work, combine ideas, present a project and assess it and a contribution of each student in this work. 
Differences: satisfies needs in self-realization, combines several diverse methods, students work independently, a teacher's consultation is given if necessary. A teacher's role changes, he acts as a team member. He is at the head of such association. A project may be realized not only by one group but by a whole course. Students combine in groups voluntary. Each contribution is assessed.

\section{10. Ideas synthesis}

\section{Ukraine}

Aim: solution of complicated problems.

Organization: Students combine in 5-6 groups and expert one. Groups give their variant of a problem solution to other groups for they could add, agree or refuse something. An expert group also works at a problem solution for comparing own variant with a groups' one and make a general report to discuss it in a whole group further.

Differences: besides groups, discussing a question, there is a group of experts of potent students that compare given variants with own one and make a generalization, discussed by a whole group.

Graffiti

\section{Germany}

Aim: to create possibilities for congeniality in a group. Potent students fix knowledge, helping weaker ones to master a new material.

Organization: Students combine in 5-6 groups. They receive a letter with a problem and they offer own variants of solution on it. This letter is then given to another group that adds it with own ideas. At the end a group discusses all received answers, making a general conclusion.

Differences: there are no expert groups.

\section{11. Partner (pair) work}

\section{Pair work}

\section{Ukraine}

Aim: to fix, to check up acquired knowledge. It favors the development of skills to communication, to share ideas with a partner, ability to convince and to conduct a discussion, to consider a text, task, document, to determine a partner's attitude to a given reading, lecture or other learning activity.

Organization: a teacher gives a question for a discussion, explains facts, presented in a task. Students must come to consent at expressing thoughts to each other. After the end, ideas on a topic are shared with a group.

Rotation threes are a variant of pair work

Organization: students combine in threes to create a circle. Each of them answer a question by turn, then students calculate themselves as first, second, third and ones with number 3 are rotated in other three. The number of questions is equal to the one of students' movements. A common solution is obligatory after discussion.

Differences: a teacher gives a question for a discussion, explains facts, presented in a task. Students' rotation by circle. A common solution is obligatory. Sometimes they go over to a collective discussion.

\section{Partnerbriefing}

\section{Germany}

Aim: it favors the development of the ability to work in a team, improvement of language competences, skill to master a new material without a teacher's control.

Organization: this work type starts from a conversation or lecture about new topic. The first phase: individual work. A teacher chooses two texts that contain questions, important for students. He explains the essence of this method and give many-colored cards to students for both teams have two texts. Students work with this material then try to explain what they have read in own words. The other variant is possible: one student explains a learning text, read by him, another 
one listens, a third one generalizes what was heard. The third variant: one student retells a text, another one listens and generalizes, then they share own ideas and present results to a group.

Stationenlernen is also the variant of pair work. Students receive tasks, placed along a lecture hall that reminds of railway stations. There may be $4-8$ stations or tasks, they form a single topic. Tasks differ not only by content but also by perception channel (audio, video materials) or may be visualized on a stand. Students go from one station to another in pairs or small groups, carrying out tasks. This work consists of the following phases: preparation, realization, presentation, summing up. Its tasks are differentiated for potent and weak students. At the beginning students work individually then take part in a common work. The advantage for this work for a group is a possibility to choose tasks taking into account students' interests and language skills. The similar methods are Lernzirkelund and Galeriegang.

Differences: students work with a new material without a teacher's control, freely communicate, time passes unnoticeably due to work types changes. Tasks differ not only by content but also by perception channel (audio, video materials). Students go from one station to another in pairs or small groups, carrying out tasks. At the beginning students work individually then take part in a common work. They have a possibility to choose tasks taking into account own interests and language skills.

\section{12. Aquarium}

Ukraine

Aim: the development of communicative skills, improvement of the ability to discussion and argumentation of own thought.

Organization: A teacher forms groups with 4-6 persons that seat in the center, gives them tasks for a discussion and sets 3-5 min time, during which they must attain a common solution and to present it. Then a teacher addresses to observers group, who also considered this problem. They also discuss it aloud then an external group returns at own places. A teacher ask all: are they agree with an idea, was this idea properly argued, what argument is most convincing.

Differences: this technology is directed on fixation of a material, improvement of the ability to discussion and argumentation of own thought.

Fishbowl-Diskussion

\section{Germany}

Aim: the development of skills of foreign communication in a group, elaboration of social competence and setting of friendly relations.

Organization: 5-7 students create a circle, if such task was always used in a group, their number may be more; there is a discussion moderator in a circle and one free chair in the center, if a student from observation group wants to make any contribution in a discussion in question form. Then he returns to observation group, which members receive letters in which they make notes about behavior of a group and each of its participants separately. Results are summed up in two stages:

1. Results of a discussion in internal group.

2. Results from observation group, consisted of two items: what strengths were observed in participants of internal circle? What may be done to improve participants' language behavior?

Differences: an observer from external circle may contribute as a question that may direct a discussion; observers analyze participants' behavior, their activity. This group also studies by directed observation.

\section{13. Roundabout}

\section{Ukraine}

Aim: to discuss an acute problem with generalization of contradictory positions, to collect information for checking up knowledge on any topic, for development of skills of argumentation of own position.

Organization: students combine in two circles, internal and external and seat faces to each other. Students in internal group are followers of one point of view and students in external circle - of an opposite one. After a signal, partners change places. The external circle is movable. 
Before ending the work, students must carry out tasks and develop a system of arguments and gain experience of communication with different partners. At the end separate answers and questions that turned out too complicated or, on the contrary, effective, are listened.

Differences: participants' rotation, getting experience of communication with different partners, listening of separate answers for generalization of existent questions.

\section{Germany}

Aim: to discuss certain questions, to fix gained foreign language skills of students.

Organization: for realizing this question, a group is placed by circle, questions are put to a student by choice, he/she answer it and, in own turn, may put the same question to one, who asked it.

Differences: fixation of foreign language skills at a discussion, rotation is absent.

\section{Discussion of results}

Thus, having considered the definitions of the notion "interactive technologies", the types of technologies, used in Ukrainian and German HEIs, we made the following conclusions:

Characterizing the notion "interactive technologies", native scientists accent that technologies must have a problem-search nature, so intersubjective interaction will be present. As to German scientists, they pay attention to personal interests, needs and also combination of cognitive, social and emotional components at the study that, from their point of view, favor successful interpersonal interaction in foreign language the best.

At using interactive technology, connected with audio materials, the aim of German HEIs is an acquaintance with another culture, customs, personality of performer of a text (song, verse), his biography. If technologies are connected with video materials, the aim is to study cinema or literary genres, their influence on an audience, types of emotional reactions, behavior inherent to certain situation and development of communicative skills using role games, dramatization. Students have also a possibility to use audio and video materials at projects. For Ukraine the work with audio and video material provides fixation of phonetic, lexical, grammatical skills, check up of a text understanding by texts tasks realization, taking away of psychological discomfort.

In a situation of modeling technologies (simulation or imitation, role game) in Ukrainian HEIs the accent is made on illustration of certain phenomena and mechanisms of making decisions by representatives of social institutions, giving students a possibility to get used to a problem deeply and understand casual connections. Students prepare beforehand for playing roles at this type of activity, as opposite to Germany that doesn't aim for perfect realization of activity by accurate preparation but only for providing successful interpersonal interaction at a simulation of behavior of people of different specialties in certain institutions. Simulation as a staging is prepared during certain time but roles distribution is a surprise for students, they get to know about own role directly before a simulation, thus they play certain plot without preliminary preparation, spontaneously demonstrating different emotions, reactions, language behavior and gain experience, improving their communicative competence. The features of debatable questions discussion in Germany is an absence of distinct imposed plan of it. A teacher may only direct it using directing questions; students choose a position that they consider as a correct one, but may change opinion at a discussion. Speech performance by barristers from both sides and ability to answer opponents' questions persuasively has also an influence on making a correct decision as to a discussed problem. At a discussion, students may move along a lecture hall that allows them to express ideas freely and without restrain, but the main thing is not to express arguments but the ability to defend and ground own position, tolerant attitude to another idea.

Discussion or debate at studying in Ukraine provides a distinct plan, organization, guidance of a teacher. Students acquaint with a material that presents point of views of different scientists before a discussion, but they may add something own, in such a way deepening knowledge on a problem. A teacher divides students in groups that present the positions "for" and "against", and students must present arguments to incline opponents on own side, at the end of a discussion at a vote, each member of a group makes a decision as to a problem. 
Interactive technologies of collective-group study ("Incomplete sentences", "Brain storm"), used in Germany, are directed on training lexical and grammatical skills by fixing certain constructions, phrases, dictums at a discussion of conversational topic or at the beginning of a lesson to fill a vocabulary of this topic. "Incomplete sentences" and "Brain storm" have absolutely another direction in Ukrainian HEIs, allowing students to express own idea as to a discussed topic in easy conditions during a limited period of time. Then ideas are discussed more detail and the very process of discussion is assessed by a teacher.

The corporative studying technologies ("Project", "Ideas synthesis", "Graffiti", "Rotation threes" "Ротаційні трійки”, "Stationenlernen“, "Partnerbriefing“, "Aquarium”, "FishbowlDiskussion", "Roundabout") in Germany help to satisfy needs in self-realization, open possibilities for congeniality in a group, responsibility for a common business, for successful work in a team, taking into account interests, needs and language skills of students and for competences improvements. Tasks differ not only by content but also by perception channel. Use of these technologies in the learning process of Ukrainian HEIs allows to raise students' interest to the study, to foreign language, to solve complicated questions, to develop creative abilities, communicative skills and research on a problem.

Strengths of this research are: Originality of information, gained directly during observation on using these technologies at lessons of foreign language and at interrogation and conversations with teachers and students about special features of these technologies. This experience may be used at lectures and seminars on pedagogy, at writing articles, handbooks, at practical activities of foreign language, because the use of these technologies allows to develop creative abilities, communicative skills, raise students' interest to the study, to foreign language, to complicated problems solution.

Weak sides are: lack of time for more assiduous observation over use of these technologies at other departments of the university.

Further studies on this subject provide an investigation of features of interactive technologies types use at different departments of the university in Germany.

\section{Conclusions}

As a result of studies:

1. The notion "interactive technologies" in interpretations of foreign and native scientists was considered.

This notion is interpreted by native scientists as intersubjective interaction of a problem-search nature; as to German ones, they use a humanistic and personal-oriented approach to intersubjective interaction.

2. The technologies, most often used in the educational process of German and Ukrainian HEIs were revealed.

There are technologies, connected with audio, video materials use, technologies of situational modeling (simulations or imitations, role game), technologies of debatable questions consideration (discussion, debate), technologies of collective-group study ("Incomplete sentences", "Brain storm"), technologies of cooperative study ("Project", "Ideas synthesis", Graffiti”, "Rotation threes", "Stationenlernen", "Partnerbriefing“, "Aquarium", "Fishbowl-Diskussion“, "Roundabout”).

3. Common features and differences in using interactive technologies in Germany and Ukraine were found.

At using audio materials in German HEIs the aim is the acquaintance with another culture, which language is studied. If there are technologies, connected with using video materials, the aim is the study of cinema/literature genres. For Ukraine the work with audio and video material provides fixation of skills and taking away of psychological discomfort.

In situation of modeling technologies (simulation or imitation, role game) in Ukrainian HEIs the accent is made on illustration of certain phenomena and mechanisms of making decisions by representatives of social institutions by careful preparation, and as to Germany, a teacher aims for gaining experience of successful interpersonal interaction at a simulation of behavior of people of different specialties. 
The features of debatable questions consideration (discussions, debates) at studying in Germany is an absence of distinct plan of it. Students may move along a lecture hall that allows them to express thoughts freely and easy. Discussion of debate in Ukraine provides a distinct plan, organization, guidance of a teacher.

Interactive technologies of collective-group study, used in Germany, are directed on training of lexical and grammatical skills, in Ukrainian HEIs "Incomplete sentences" and "Brain storm" allows students to express own opinion about discussed topic in easy conditions or to generate ideas about it during a limited period of time as more as possible.

Cooperative studying technologies in Germany help to satisfy needs in self-realization and to improve competences at working in a team. The use of these technologies in the educational process of Ukrainian HEIs allows to raise interest to studying foreign language, to complicated questions solution, to develop creative abilities.

\section{Acknowledgment}

I would like to express gratitude to my supervisor Prof. Dr. Kurliand Z. N. for help, creative inspiration at our work on my thesis, German professors Prof. Dr. L. Schifler, Prof. Dr. M. Sambanis, Prof. Dr. Caspari and other lecturers of the Free university of Berlin for cooperation and enrichment of experience.

\section{References}

[1] Honcharov, S. (2006). Interaktyvni tekhnolohiyi navchannya v kredytno-modul'niy systemi orhanizatsiyi navchal'noho protsesu. Rivne: NUVHP, 172.

[2] Hrabovs'ka, S. (2005). Interaktyvne navchannya v vuzi: problemy i perspektyvy. Visnyk L'vivs'koho universytetu. Seriya pedahohichna, 15, 171-176.

[3] Pometun, O. (2006). Suchasnyy urok. Interaktyvni tekhnolohiyi navchannya. Kyiv: A.S.K., 192.

[4] Fedorchuk, E. (2003). Vykorystannya interaktyvnykh metodiv ta mul'tymediynykh zasobiv u pidhotovtsi pedahoha. Kamianets-Podilskyi: Abetka - Nova, 208.

[5] Bausch, K. R. (2007). Handbuch Fremdsprachenunterricht. Tubingen uni Basel: A. Francke.

[6] Helene, Decke-Cornill. (2010). Fremdsprachendidaktik. Tübingen: Narr.

[7] Mattes, W. (2014). Methoden für den Unterricht. Paderborn: Schöningh.

[8] Schiffler, L. (2012). Effektiver Fremdsprachenunterricht. Tübingen: Narr.

[9] Schnelle, C. (2010).Unterricht als Interaktion. Heilbrunn: Klinkhardt.

[10] Thaler, E. (2012). English unterrichten: Grundlagen-Kompetenzen-Methoden. Berlin: Cornelsen. 